\title{
Right heart catheterization procedures in patients with suspicion of pulmonary hypertension - experiences of a tertiary center
}

\author{
Maciej Grymuza ${ }^{1}$, Katarzyna Małaczyńska-Rajpold ${ }^{1}$, Stanisław Jankiewicz ${ }^{1}$, Andrzej Siniawski ${ }^{2}$, \\ Marek Grygier², Przemysław Mitkowski², Marta Kałużna-Oleksy², Maciej Lesiak², Tatiana Mularek-Kubzdela², \\ Aleksander Araszkiewicz ${ }^{2}$
}

${ }^{1}$ Department of Cardiology, University Hospital of Lord's Transfiguration, Poznan, Poland

${ }^{2}$ Department of Cardiology, Poznan University of Medical Sciences, Poznan, Poland

Adv Interv Cardiol 2017; 13, 4 (50): 295-301

DOI: https://doi.org/10.5114/aic.2017.71610

\begin{abstract}
Introduction: Right heart catheterization (RHC) is an invasive procedure providing direct and accurate measurements of hemodynamics of the cardiovascular system. Acute pulmonary vasoreactivity testing (APVT) following basal RHC in some patients is an established tool evaluating the reversibility of hypertension in the pulmonary vasculature.

Aim: We sought to assess the most common indications, vascular approaches and complications during RHC in a single high-volume center.

Material and methods: A total of $534 \mathrm{RHC}$ procedures in 348 patients (64\% male) were performed. The prospective registry was carried out for 28 months. Collected data included indications for RHC, vascular approaches, hemodynamic and clinical data, complications and response of pulmonary vessels in APVT.

Results: In 401 (75\%) procedures pulmonary hypertension (mean pulmonary artery pressure (mPAP) $\geq 25 \mathrm{~mm} \mathrm{Hg}$ ) was confirmed. Left heart failure was the most common indication (55.8\%), mainly ischemic (26\%) or dilated cardiomyopathy (19.9\%). Other indications included a suspicion of arterial (21.7\%), or chronic thromboembolic pulmonary hypertension (14.6\%). The right internal jugular vein approach was used in $89.1 \%$ of procedures. Acute pulmonary vasoreactivity testing was performed in 143 patients, and it was positive in $67(46.9 \%)$ cases. Complications occurred in 21 (3.9\%) procedures and included pulmonary edema (0.2\%), pneumothorax (0.2\%) and puncture of the artery followed by the insertion of a vascular sheath (0.4\%), atrial arrhythmia (0.2\%), superior vena cava dissection ( $0.2 \%)$, incidental artery puncture $(1.1 \%)$ and local hematoma $(2.2 \%)$.

Conclusions: The most frequent indication for RHC was left heart failure, and the most common approach was the right internal jugular vein. $\mathrm{RHC}$ is safe procedure with a low rate of major complications.
\end{abstract}

Key words: complications, indications, acute pulmonary vasoreactivity testing.

\section{Introduction}

Right heart catheterization (RHC) is widely used in cardiology, cardiac and thoracic surgery, pulmonology and intensive care, as it provides useful data concerning hemodynamics of the cardiovascular system. This examination was carried out for the first time by Forssmann in 1929, and then further developed by Cournand and Richards [1]. Right heart catheterization is an invasive procedure that enables direct and accurate measurement of the condition of the right heart and pulmonary vessels and indirectly provides information about the left heart [2].
Indications for this examination in adults comprise: 1) diagnosis of pulmonary hypertension, establishing its type, severity and further monitoring, 2) evaluation prior to correction of cardiac shunt defects and 3) eligibility for heart and/or lung transplantation [3]. In some cases baseline hemodynamic evaluation is followed by acute pulmonary vasoreactivity testing (APVT). It assesses the ability of pulmonary arteries to dilate after the administration of a vasodilating drug (e.g. inhaled nitric oxide or iloprost, intravenous nitroglycerin or sodium nitroprusside) [4-7]. Depending on the underlying condition, the purpose of APVT varies from the indication for use

Corresponding author:

Aleksander Araszkiewicz MD, PhD, Department of Cardiology, Poznan University of Medical Sciences, 1/2 Długa St, 61-848 Poznan, Poland, phone: +48 608574 375, fax: +48 6185490 94, e-mail: aaraszkiewicz@interia.pl

Received: 29.08.2017, accepted: 13.10.2017. 
of calcium channel blockers in pulmonary arterial hypertension, through the evaluation for correction of cardiac shunt defects to heart and/or lung transplantation [8]. The catheter is placed in the right heart mostly through a central vein [9]. Right heart catheterization is rarely associated with any serious complications; however, its rate is dependent on the clinical status of patients and the operator's and center's experience. Numerous conditions lead to elevation of the pressure in pulmonary arteries and become indications for RHC; their frequency varies in the literature, as does the number of complications [10-14].

\section{Aim}

We sought to assess the indications for RHC, as well as occurrence of adverse events, especially serious ones. This study reports the results of RHC procedures in a tertiary hospital taking into consideration the most common underlying conditions, vascular approaches and safety of this procedure.

\section{Material and methods}

A single-center prospective registry was carried out from January 2015 to May 2017. Fully informed, written consent for the procedure was obtained from each patient. Three hundred and forty-eight ( $64 \%$ male) patients at the mean age of $54.6 \pm 12.4$ years with suspicion of pulmonary hypertension had RHC using a Swan-Ganz catheter performed. Collected data included basic demographic data (gender, age) and clinical data such as body surface area, heart rate, systemic blood pressure, comorbidities, pharmacological treatment, indications for RHC, vascular approaches and complications of the procedure. Routes of access were the internal jugular vein, venous angle, depending on the operator's preference, and the femoral vein, if additional conditions were present. Adverse events were classified as major - pulmonary edema, pneumothorax and puncture of carotid artery followed by the insertion of a vascular sheath - and minor: atrial arrhythmia, superior vena cava dissection, incidental artery puncture and local hematoma. Each complication was observed and intervention was undertaken, if necessary. Catheterizations were carried out in the catheterization laboratory, mostly by 5 experienced operators. Some patients were on anticoagulant therapy; it was stopped before the procedure without bridging and started again after $6 \mathrm{~h}$, if no complications occurred. Right heart catheterization was postponed if international normalized ratio (INR) $>2$. Strict aseptic technique and local anaesthesia with lidocaine $2 \%$ were used. A $7 \mathrm{Fr}$ sheath was introduced with the modified Seldinger technique. Ultrasound guidance was used prior to $34 \%$ of procedures; more often the position of the catheter was confirmed in fluoroscopy. Measured parameters concerning pulmonary circulation were as follows: mean right atrium pressure, right ventricle pressure (systolic, diastolic and end-diastolic), pulmonary artery pressure (systolic, diastolic and mean), and wedge pressure obtained after catheter balloon inflation at the end of expiration. Cardiac output (CO) was measured with thermodilution with cold saline or the direct Fick method for patients with intracardiac shunts, whereas the cardiac index $(\mathrm{Cl})$, pulmonary (PVR), systemic vascular resistance (SVR) and transpulmonary gradient (TPG) were estimated based on previous measurements. After removal of the sheath, pressure was applied to the site and an occlusive dressing was used. The diagnosis of pulmonary hypertension was established if mean pulmonary artery pressure equaled or exceeded $25 \mathrm{~mm} \mathrm{Hg}$. Some patients had an acute pulmonary vasoreactivity test with iloprost or nitroglycerin performed. APVT was performed in all patients with idiopathic or familial pulmonary (pre-capillary) hypertension if pulmonary vascular resistance was $\geq 2.5$ Wood's units or transpulmonary gradient $>12 \mathrm{~mm} \mathrm{Hg}$ in patients with pulmonary hypertension due to left heart diseases. Iloprost was administered in the dose of $5 \mu \mathrm{g}$ inhaled within about $7 \mathrm{~min}$, and nitroglycerin was administered according to the protocol: in 10-minute IV infusion of $0.2 \mathrm{mg} / \mathrm{ml}$ concentration with $20 \mathrm{ml} / \mathrm{h}$ flow, which resulted in the total dose of 0.67 $\pm 0.13 \mathrm{mg}$ being given. The administration was stopped if the systemic systolic blood pressure fell below $85 \mathrm{~mm} \mathrm{Hg}$. Measurements were repeated again 10-15 min after administration of a vasodilator. Depending on the underlying condition the response of the vessels was assessed according to current guidelines. In precapillary pulmonary hypertension positive criteria for APVT were as follows: mean pulmonary artery pressure decrease of at least $10 \mathrm{~mm} \mathrm{Hg}$ and below $40 \mathrm{~mm} \mathrm{Hg}$ with increased or unchanged cardiac output. For postcapillary pulmonary hypertension PVR and TPG were taken into assessment and the APVT was considered positive if they decreased to $<2.5 \mathrm{WU}$ and $<12 \mathrm{~mm} \mathrm{Hg}$ respectively, without a systemic systolic blood pressure drop below $85 \mathrm{~mm} \mathrm{Hg}$. Continuous variables are expressed as mean or median and categorical data are reported as frequencies and percentages.

\section{Statistical analysis}

Descriptive statistics were completed using Statistica 12, Statistica, USA, Oklahoma, Tulsa.

\section{Results}

Five hundred and thirty-four right heart catheterizations were carried out comprising $6 \%$ of all procedures in our catheterization laboratory. Those procedures were performed in 348 patients (64\% male). One hundred and eight patients had more than one RHC performed (2-6 procedures). Serial assessment were required in: 1) monitoring and requirement of modifications of treatment and aggravations of pulmonary arterial hyperten- 
sion (PAH) as well as 2) according to ISHLT guidelines, monitoring of patients (every 3-6 months) on hold for heart transplantation [15]. Pulmonary hypertension was confirmed in $75 \%(n=401)$ of procedures and in $10 \%$ $(n=56)$ of cases mean pulmonary artery pressure of unclear significance ( $25 \mathrm{~mm} \mathrm{Hg}<\mathrm{mPAP} \geq 21 \mathrm{~mm} \mathrm{Hg}$ ) was present. The results of RHC are shown below (Table I). Only in one case was the examination not performed due to pulmonary valve stenosis. To estimate cardiac output the thermodilution method was used in 97\% ( $n=518)$ of catheterizations, and the direct Fick method in $3 \%$ $(n=16)$ of procedures. Arterial blood gases were taken before CO measurement in 36\% ( $n=194)$ of catheterizations from patients who suffered from pulmonary arterial hypertension or chronic thromboembolic pulmonary hypertension. At the time of $53 \%(n=281)$ of procedures patients were on chronic anticoagulant therapy, which was stopped before and introduced after the procedure as described previously. $3.7 \%(n=20)$ of procedures were managed, while clopidogrel therapy was applied, without stopping. Pulmonary circulation targeted therapy was given in 230 patients and $38 \%(n=204)$ of interventions; the drugs were sildenafil, treprostinil, bosentan, epoprostenol, iloprost, riociguat, macitentan single or combined. Dopamine and dobutamine were administered during examination in $1.3 \%(n=7)$ of cases, and in $1.1 \%(n=6)$ of cases one of those drugs was given.

All procedures were elective, done in an inpatient setting. The most frequent indication was left heart failure: $55.8 \%(n=298)$ of all procedures (Figure 1$)$. The etiology of this condition was ischemic cardiomyopathy in $26 \%$ $(n=139)$ of cases, then dilated cardiomyopathy in $19.9 \%$ $(n=106)$ and hypertrophic cardiomyopathy in $3.6 \%$ $(n=19)$ (Figure 2$)$. In this group elevated pulmonary pressure was present after heart transplantation in $2 \%$ $(n=11)$ of patients. Other indications were: suspicion of arterial $21.7 \%(n=116)$, and chronic thromboembolic pulmonary hypertension $14.6 \%(n=78)$. Much less common were interstitial lung diseases: idiopathic pulmonary fibrosis in $3.6 \%(n=19)$ and systemic sclerosis in $3.4 \%(n=18)$ (Figure 3$)$.

The vascular approach of choice was the right internal jugular vein in $89.1 \%(n=476)$ with limited participation of the venous angle in $9.2 \%(n=49)$, and only minimal use of the femoral vein $(1.1 \%, n=6)$ and left internal jugular vein $(0.6 \%, n=3)$.

Acute vasoreactivity testing of pulmonary vessels was performed in 143 procedures, 62\% $(n=89)$ with iloprost and $38 \%(n=54)$ with nitroglycerin. Positive criteria for APVT were noted in $45.4 \%(n=65)$ of cases regardless of the underlying condition or applied drug. This examination was carried out in $80.4 \%(n=115)$ of patients with postcapillary pulmonary hypertension, who were evaluated for heart transplantation and in $19.6 \%(n=28)$ of patients with precapillary pulmonary hypertension to de-
Table I. Mean values and standard deviation of parameters obtained during $\mathrm{RHC}$

\begin{tabular}{|c|c|c|}
\hline Parameter & $\begin{array}{l}\text { Mean } \\
\text { value }\end{array}$ & $\begin{array}{l}\text { Standard } \\
\text { deviation }\end{array}$ \\
\hline Heart rate [/min] & 75.1 & 12.9 \\
\hline Systemic blood pressure [mm Hg] & 95.6 & 15.6 \\
\hline Mean right atrium pressure $[\mathrm{mm} \mathrm{Hg}]$ & 8.6 & 6.8 \\
\hline \multicolumn{3}{|l|}{ Right ventricle pressure [mm Hg]: } \\
\hline Systolic & 55.4 & 40.2 \\
\hline Diastolic & 7.1 & 7.5 \\
\hline Mean & 13.1 & 7.9 \\
\hline \multicolumn{3}{|l|}{ Pulmonary artery pressure [mm Hg]: } \\
\hline Systolic & 53.7 & 22.9 \\
\hline Diastolic & 24.7 & 10.9 \\
\hline Mean & 36.8 & 14.8 \\
\hline Wedge pressure [mm Hg] & 15.6 & 8.5 \\
\hline Transpulmonary gradient [mm Hg] & 21.3 & 15.4 \\
\hline Cardiac output [l/min] & 5.5 & 1.7 \\
\hline Cardiac index [l/min] & 2.9 & 0.8 \\
\hline $\begin{array}{l}\text { Pulmonary vascular resistance } \\
{\left[\text { dyn } \cdot \mathrm{s} / \mathrm{cm}^{5} \cdot \mathrm{m}^{2}\right]}\end{array}$ & 333.5 & 317.4 \\
\hline $\begin{array}{l}\text { Systemic vascular resistance } \\
{\left[\mathrm{dyn} \cdot \mathrm{s} / \mathrm{cm}^{5} \cdot \mathrm{m}^{2}\right]}\end{array}$ & 1336.4 & 451 \\
\hline
\end{tabular}

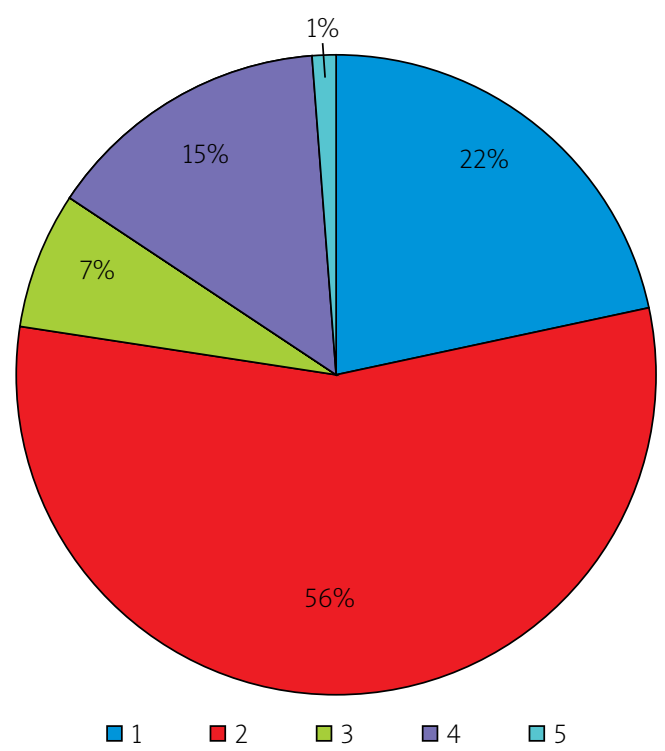

Figure 1. Classes of pulmonary hypertension diagnosed in examined patients. Class 1 - pulmonary arterial hypertension, class 2 - pulmonary hypertension due to left heart disease, class 3 - pulmonary hypertension due to lung diseases and/or hypoxia, class 4 - chronic thromboembolic pulmonary hypertension, class 5 - pulmonary hypertension with unclear mechanism 


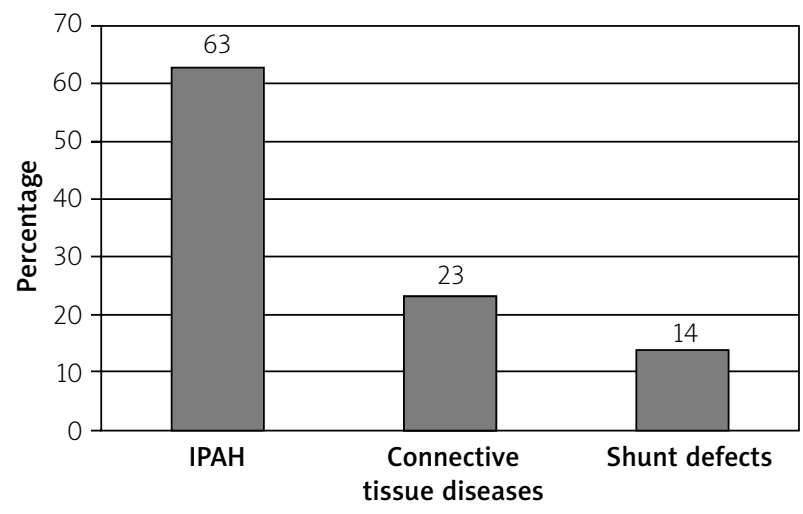

Figure 2. Conditions qualified as class $1 \mathrm{PH}$ (precapillary $\mathrm{PH}$ ). Connective tissue diseases are systemic sclerosis, systemic lupus erythematosus, Sjögren disease and rheumatoid arthritis. Shunt defects are atrial septal defect, ventricular septal defect, patent ductus arteriosus and atrioventricular septal defect

termine the indication for treatment with calcium channel blockers. Positive criteria were noted in 53\% $(n=61)$ and $14.3 \%(n=4)$ of procedures, respectively (Table II).

Complications were noted in 21 (3.9\%) interventions. The major ones were as follows: pulmonary edema, pneumothorax occurring in one patient each and puncture of the artery followed by the insertion of a vascular sheath in two cases; one was the carotid artery and the other the subclavian artery. Those complications caused discontinuation of the procedure. In the first case hypertrophic cardiomyopathy was the underlying condition of a 56-year-old patient, who developed pulmonary edema during acute vasoreactivity testing with iloprost. Introduced management included diuretics, oxygen, morphine and prolonged hospitalization. Artery puncture with the insertion of a $7 \mathrm{Fr}$ vascular sheath in one case was closed with the StarClose SE Vascular Closure

Table II. Response to APVT according to applied drug and type of pulmonary hypertension

\begin{tabular}{lcc} 
Parameter & Iloprost & Nitroglycerin \\
\hline Precapillary PH: & $26(93 \%)$ & $2(7 \%)$ \\
\hline Number of patients & $15.4 \%(n=4)$ & 0 \\
\hline $\begin{array}{l}\text { Percentage of positive } \\
\text { criteria of APVT }\end{array}$ & $84.6 \%(n=22)$ & $100 \%(n=2)$ \\
\hline $\begin{array}{l}\text { Percentage of negative } \\
\text { criteria of APVT }\end{array}$ & $63(55 \%)$ & $52(45 \%)$ \\
\hline $\begin{array}{l}\text { Postcapillary PH: } \\
\text { Number of patients }\end{array}$ & $46 \%(n=29)$ & $61.5 \%(n=32)$ \\
\hline $\begin{array}{l}\text { Percentage of positive } \\
\text { criteria of APVT }\end{array}$ & $54 \%(n=34)$ & $38.5 \%(n=20)$ \\
\hline $\begin{array}{l}\text { Percentage of negative } \\
\text { criteria of APVT }\end{array}$ & &
\end{tabular}

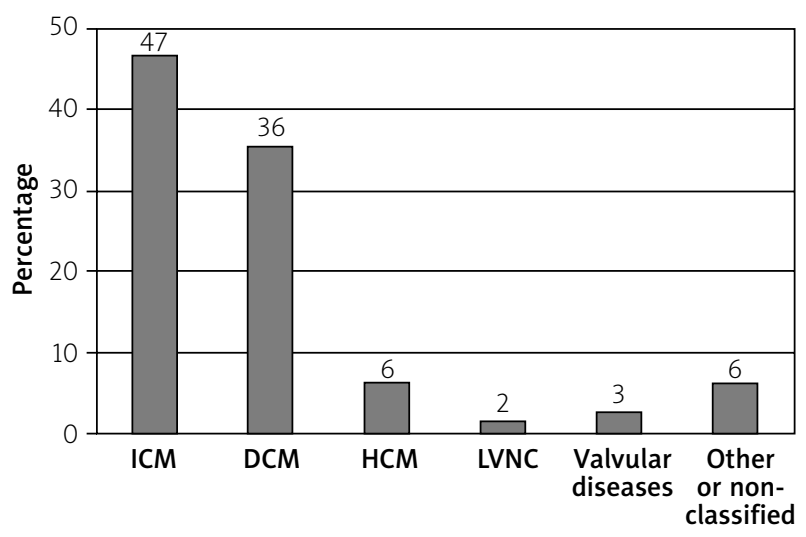

Figure 3. Conditions qualified as class $2 \mathrm{PH}$ (postcapillary $\mathrm{PH}$ )

ICM - ischemic cardiomyopathy, DCM - dilated cardiomyopathy, HCM - hypertrophic cardiomyopathy, LVNC - left ventricular non-compaction cardiomyopathy.

System (Abbott Vascular, Santa Clara, CA, USA) and verified with angiography, while in another case the sheath was removed and prolonged manual compression was applied. None of those patients presented any neurological defects or hematoma at the injection site. Despite those complications, examinations were completed after the patient's stabilization, during the same hospitalization. Pneumothorax was diagnosed after venous angle puncture. The patient was intubated due to respiratory failure, drugs were applied (oxygen, theophylline, morphine, salbutamol), drained and he was transferred to the intensive care unit. Minor complications were present in 17 procedures and included mild, spontaneously resolved arrhythmia in $1(0.2 \%)$ procedure, superior vena cava dissection in $1(0.2 \%)$ procedure, local hematoma in $9(1.7 \%)$ patients, which were of minimal danger and did not require any intervention, and incidental artery puncture in $3(0.6 \%)$ patients; in those cases the needle was immediately removed and compression was applied. In $3(0.6 \%)$ cases both hematoma and artery puncture were present in one patient. Superior vena cava dissection was noted after right internal jugular vein puncture and catheter introduction. Dissection reached the right atrium, did not bring any other complications and the procedure was continued. We did not observe more frequent complications if repetitive catheterizations were performed. No patient presented pulmonary hemorrhage, pulmonary artery rupture, air embolism or infection. No deaths directly associated with $\mathrm{RHC}$ or its complications were noted.

\section{Discussion}

The main findings of this study are as follows: 1) Left heart diseases are the most common reasons for performing RHC in our center, 2) The right internal jugu- 
lar vein is a safe and easily reached access, 3. RHC performed in our center does not lead to fatal complications and major complications are rare.

In the vast majority of cases in which right heart catheterization was performed, there were underlying cardiology conditions: heart failure, and to a lesser degree pulmonary arterial hypertension and chronic thromboembolic pulmonary hypertension (CTEPH). Indications presented by other authors vary to a great extent. In a large, multicenter study diagnosis of left heart failure was present in less than $10 \%$, and other studies report this condition in less than $20 \%$ [10-12, 14]. Furthermore, frequency of pulmonary arterial hypertension fluctuates in other research from $3.5 \%$ to $66 \%$, being particularly similar to our in the study of Lee $[10-12,14,16]$. The RHC is also obligatory in diagnosis of CTEPH; this condition is quite infrequent, yet as an indication for $\mathrm{RHC}$ in our center the frequency is similar to others (13\% vs. $14.6 \%$ ) $[11,17]$. Frequency of evaluation of intracardiac shunts in the literature varies from $3 \%$ to $60 \%$; our results are comparable to the research of Shah et al. (2.9\% vs. $3 \%)$ $[12,16]$. This variety in percentage of indications occurs as different reports present various groups of patients dependent on center type and profile (its reference, transplant center), wards where RHC was carried out (cardiology, intensive care unit, pulmonology), patients' condition: RHC acute or planned performance, in- or outpatient RHC, and number of patients.

The results of the present study indicate that the most common approach was the right internal jugular vein; this approach is suggested in ESC as well as in local recommendations $[3,18]$. Concerning this aspect, our study can be compared to other analyses. Ranu et al. used this access in 330 out of 349 patients in their analysis, the only alternative access was the left internal jugular vein [19]. Some centers adopt the subclavian vein as often as the femoral vein, but still they point out that the latter is associated with greater risk of infectious and thrombotic complications [20]. In another group of 295 right heart catheterizations there was a slight preference for neck access (174) over arm access (121) [10]. In the prospective arm of a large, multicenter study, which included 1491 patients, the internal jugular vein was used in more than $70 \%$ of procedures; less common were brachial, femoral and subclavian accesses [14]. Basilic veins were not used in any patient in our center. However, some centers prefer this access to others, but even then the femoral vein is also adopted $[11,16]$. The right internal jugular vein is a reasonable approach regarding recommendations as well as previous studies.

A vasoreactivity test was carried out in 143 patients; $45.5 \%$ of them were classified as responders, $37.1 \%$ with iloprost and $59.3 \%$ with nitroglycerin. The latter is not standard recommended vasodilator, although it was used in APVT in previous studies on small groups of patients and is mentioned in some local guidelines
$[5,21]$. The percentage of reversibility achieved in other studies is comparable to ours, but the agents applied differ, as nitric oxide and nifedipine were also administered $[22,23]$. Concerning patients suffering from PAH, iloprost is rarely used as a vasodilator; in some analyses its effectiveness is similar to the present study (14\% vs. $15.4 \%$ ). Another compound, epoprostenol, is reported to be a more potent agent, reaching $31 \%$ reversibility $[6,24]$. The study of Hoeper et al. characterized iloprost to be more efficient than nitric oxide [25]. Nonetheless, some research on candidates for heart transplantation reported the use of not only nitroglycerin and prostacyclin, but also sodium nitroprusside, which was not assessed in the present study [26]. Comparable outcomes were achieved by Torres Macho et al. - almost $50 \%$ of patients who happened to be responders (vs. 53\% in this study) used vasodilators including nitroglycerin, sodium nitroprusside and prostacyclin, but no significant differences between groups in response to the vasoreactivity test were noted [5]. Some studies carried out on small groups of patients with slightly different vasodilators show a higher percentage of reversibility of this type of pulmonary hypertension - almost 80\% [26].

The frequency of complications noted in the present study was nearly $4 \%$; it is more than in the study by Hoeper et al., who noted about $1 \%$ complications, and some other studies with a similar frequency of adverse events, which is $0.6-1.8 \%$ [10-12, 19]. However, our results in terms of percentage of complications are comparable to some others, reaching 3-6\% [27-29]. McGee and Gould in their review noted frequency of complications even up to $20 \%$, depending on the access site [13]. Frequency of puncture of the artery followed by the insertion of a vascular sheath is noted in the literature at less than $1 \%$. In a retrospective 11 -year-long study, Bechara et al. noted this complication 12 times. Similarly to ours, they were followed by neither neurological defect nor other events, and management of this complication in their study was comparable to ours [30]. Pneumothorax is an uncommon complication, but more likely to be present if subclavian access is used [13]. A review reports this event in the mentioned approach at about 1.5-3.1\%; thus it is more than in our study and almost identical to Hoeper's [13, 14]. Pulmonary edema after pulmonary vasoreactivity testing with a prostacyclin analogue is rarely mentioned in literature [31] and superior vena cava dissection during RHC has not been reported so far.

Artery puncture is a common difficulty, especially in patients with severe hypoxemia and low $\mathrm{CO}$ as the arterial blood color and flow resemble venous ones. In observational studies, the frequency ranges from $0.1 \%$ to $9 \%$, and a review reported about $6.3-9.4 \%$ of all procedures in which the access site was the internal jugular vein [10, $13,20,27,32]$. This complication is more common in femoral access and infrequent in antecubital access [10, 20]. Local hematoma is also a common complication and our experience is comparable to others. In the present study 
it appeared in $2 \%$, while rates given in the literature are $0.1-2.2 \%[13,14]$. Likewise, arrhythmias are reported in previous studies in a similar percentage [14]. Frequency of adverse events, especially more serious, appear mainly in research in which a greater number of patients was taken into consideration $[9,13,14,33]$. Complications such as artery puncture with/without insertion of a vascular sheath depend on access site and operator's experience. Hematomas are usually not serious, but difficult to avoid and appear in most studies with similar commonness. This registry does not differ from previous studies in terms of the number of complications. Serious ones were properly managed, and did not lead to permanent disability. Remarkably, we did not observe some serious events present in other studies, such as vagal reaction, vein thrombosis, pulmonary artery rupture or transient ischemic attack and deaths associated directly with RHC.

\section{Conclusions}

Right heart catheterization is carried out in numerous conditions, particularly it is carried out in patients suffering from left heart failure, chronic thromboembolic pulmonary hypertension and pulmonary arterial hypertension, which contributes to the indications for RHC. Central venous access seems to have an acceptable safety and feasibility profile. The RHC is a harmless procedure, and complications are rare, especially when ultrasound- and/or fluoroscopy-guided. Caution is required when performing APVT in patients with left heart failure with severe restriction of the left ventricle.

\section{Conflict of interest}

The authors declare no conflict of interest.

\section{References}

1. Chatterjee K. The Swan-Ganz catheters: past, present, and future: a viewpoint. Circulation 2009; 119: 147-52.

2. Kałużna-Oleksy M, Araszkiewicz A, Migaj J, et al. "From right to left": the role of right heart catheterization in the diagnosis and management of left heart diseases. Adv Clin Exp Med 2017; 26: 135-41.

3. Galiè N, Humbert M, Vachiéry JL, et al. 2015 ESC/ERS Guidelines for the diagnosis and treatment of pulmonary hypertension. Eur Heart J 2015; 37: 67-119.

4. Costard-Jackle A, Fowler MB. Influence of preoperative pulmonary artery pressure on mortality after heart transplantation: testing of potential reversibility of pulmonary hypertension with nitroprusside is useful in defining a high risk group. J Am Coll Cardiol 1992; 19: 48-54.

5. Torres Macho J, Delgado Jimenez JF, Sanz Salvo J, et al. Effect of different pharmacologic agents to reverse severe pulmonary hypertension among end-stage heart failure patients. Transplant Proc 2009; 41: 2477-9.

6. Jing ZC, Jiang X, Han ZY, et al. Iloprost for pulmonary vasodilator testing in idiopathic pulmonary arterial hypertension. Eur Respir J 2009; 33: 1354-60.
7. Semigran MJ, Cockrill BA, Kacmarek R, et al. Hemodynamic effects of inhaled nitric oxide in heart failure. J Am Coll Cardiol 1994; 24: 982-8.

8. Kurzyna M, Araszkiewicz A, Błaszczak P, et al. Summary of recommendations for the haemodynamic and angiographic assessment of the pulmonary circulation. Joint statement of the Polish Cardiac Society's Working group on pulmonary circulation and association of cardiovascular interventions. Kardiol Pol 2015; 73: 63-8.

9. Kalińczuk Ł, Chmielak Z, Dębski A, et al. Percutaneous retrieval of centrally embolized fragments of central venous access devices or knotted Swan-Ganz catheters. Clinical report of 14 retrievals with detailed angiographic analysis and review of procedural aspects. Adv Interv Cardiol 2016; 12: 140-55.

10. Harwani N, Chukwu E, Alvarez M, Thohan V. Comparison of brachial vein versus internal jugular vein approach for access to the right side of the heart with or without myocardial biopsy. Am J Cardiol 2015; 116: 740-3.

11. Roule V, Ailem S, Legallois D, et al. Antecubital vs femoral venous access for right heart catheterization: benefits of a flashback. Can J Cardiol 2015; 31: 1497.e1-6.

12. Shah S, Boyd G, Pyne CT, et al. Right heart catheterization using antecubital venous access: feasibility, safety and adoption rate in a tertiary center. Catheter Cardiovasc Interv 2014; 84: 70-4.

13. McGee D, Gould M. Preventing complications of central venous catheterization. N Engl J Med 2003; 348: 2684-6.

14. Hoeper MM, Lee SH, Voswinckel R, et al. Complications of right heart catheterization procedures in patients with pulmonary hypertension in experienced centers. J Am Coll Cardiol 2006; 48: 2546-52.

15. Mehra MR, Kobashigawa J, Starling R, et al. Listing criteria for heart transplantation: International Society for Heart and Lung Transplantation Guidelines for the Care of Cardiac Transplant Candidates-2006. J Hear Lung Transplant 2006; 25: 1024-42.

16. Lee SH, Chun KJ, Lee DS, et al. Right cardiac catheterization using the antecubital fossa vein in Korean patients. Korean Circ J 2016; 46: 207-12.

17. Kurzyna M, Darocha S, Koteja A, et al. Balloon pulmonary angioplasty for chronic thromboembolic pulmonary hypertension. Postep Kardiol Interw 2015; 11: 1-4.

18. Kurzyna M, Araszkiewicz A, Błaszczak P, et al. Standardy hemodynamicznej i angiograficznej oceny krążenia płucnego. Kardiol Pol 2014; 72 Suppl I: 45-64.

19. Ranu H, Smith K, Nimako K, et al. A retrospective review to evaluate the safety of right heart catheterization via the internal jugular vein in the assessment of pulmonary hypertension. Clin Cardiol 2010; 33: 303-6.

20. Merrer J, De Jonghe B, Golliot F, et al. Complications of femoral and subclavian venous catheterization in critically ill patients: a randomized trial. JAMA 2001; 286: 700-7.

21. de Jonge N, Kirkels JH, Klöpping C, et al. Guidelines for heart transplantation. Neth Heart J 2008; 16: 79-87.

22. Sitbon O, Brenot F, Denjean A, et al. Inhaled nitric oxide as a screening vasodilator agent in primary pulmonary hypertension: a dose-response study and comparison with prostacyclin. Am J Respir Crit Care Med 1995; 151: 384-9.

23. Ricciardi MJ, Knight BP, Martinez FJ, Rubenfire M. Inhaled nitric oxide in primary pulmonary hypertension: a safe and effective agent for predicting response to nifedipine. J Am Coll Cardiol 1998; 32: 1068-73. 
24. Grignola JC, Domingo E, Aguilar R, et al. Acute absolute vasodilatation is associated with a lower vascular wall stiffness in pulmonary arterial hypertension. Int J Cardiol 2013; 164: 227-31.

25. Hoeper MM, Olschewski H, Ghofrani HA, et al. A comparison of the acute hemodynamic effects of inhaled nitric oxide and aerosolized iloprost in primary pulmonary hypertension. J Am Coll Cardiol 2000; 35: 176-82.

26. Murali S, Uretsky BF, Armitage JM, et al. Utility of prostaglandin E1 in the pretransplantation evaluation of heart failure patients with significant pulmonary hypertension. J Heart Lung Transplant 1992; 11: 716-723.

27. Rich S, Dantzker DR, Ayres SM, et al. Primary pulmonary hypertension. A national prospective study. 1987; 107: 216-23.

28. Elliott CG, Zimmerman GA, Clemmer TP. Complications of pulmonary artery catheterization in the care of critically ill patients. A prospective study. Chest J 1979; 76: 647-52.

29. Mark S, Calderon-Artero P, Kakinami L, et al. Review of ambulatory pulmonary artery catheterization in the management of advanced heart failure. Congest Heart Fail 2012; 18: 173-8.

30. Bechara CF, Barshes NR, Pisimisis G, et al. Management of inadvertent carotid artery sheath insertion during central venous catheter placement. JAMA Surg 2013; 148: 1063-6.

31. Strange C, Bolster M, Mazur J, et al. Hemodynamic effects of epoprostenol in patients with systemic sclerosis and pulmonary hypertension. Chest 2000; 118: 1077-82.

32. Richard C, Anguel N, Deye N, Combes A. Early use of the pulmonary artery catheter and outcomes in patients with shock. JAMA 2003; 290: 2713-20.

33. Rudziński PN, Henzel J, Dzielińska Z, et al. Pulmonary artery rupture as a complication of Swan-Ganz catheter application. Diagnosis and endovascular treatment: a single centre's experience. Adv Interv Cardiol 2016; 12: 135-9. 